\title{
MIRANDO AL CIELO SIN DEJAR EL SUELO: LOS JERÓNIMOS CORDOBESES DE VALPARAÍSO EN EL ANTIGUO RÉGIMEN, ESTUDIO PRELIMINAR Y EDICIÓN CRÍTICA DEL LIBRO PROTOCOLO DE LA COMUNIDAD
}

\author{
SOLEDAD GóMEZ NAVARRo \\ Madrid, 2014, Visión Libros/Colegio Notarial de Andalucía/Instituto Escurialense de \\ Investigaciones Históricas y Artísticas, 822 páginas. \\ ISBN 978-84-9886-763-3
}

El redescubrimiento de la historia del estamento eclesiástico en la España moderna por parte del mundo académico que tuviera lugar en los años ochenta comenzó por el análisis de los aspectos económicos, tarea en la cual los establecimientos monásticos se beneficiaron de una situación privilegiada, habida cuenta de la concentración de las fuentes en la sección Clero del Archivo Histórico Nacional. No obstante, como sucede en tantas ocasiones en la historiografía española, esta línea de trabajo, que en su momento brindara estudios modélicos como los de Maximiliano Barrio Gozalo, Gloria Franco Rubio, o Antonio Luis López Martínez, fue abandonada de una forma tan repentina como había comenzado, y a partir de los noventa la historiografía religiosa española derivaría hacia líneas más sociales y culturales que económicas, lo cual, por otra parte, no hacía más que reflejar el cambio de tendencia de los historiadores españoles, o, al menos, de los modernistas, que pasaron sin apenas solución de continuidad del mundo de la demografía y la economía al de la sociedad y las mal llamadas mentalidades.

Queda, sin embargo, mucho por hacer, aunque en los tiempos que corren sean plumas aisladas las que sigan dedicándose a la ingrata tarea de abordar cuestiones localizadas en espacios concretos, cuando la mayor parte de los historiadores, o al menos éste que escribe, nos hemos dejado seducir por los cantos de sirena de temáticas más globalizadoras y, sobre todo, asequibles a través de la red, lo que nos brinda la falsa ilusión de hablar de Mediterráneos cuando aún quedan muchas pequeñas calas y recónditas bahías por descubrir, aunque para ello sean necesarias muchas dosis de paciencia, tiempo y ganas de practicar el oficio por mera gratificación personal y por amor al objeto de trabajo, y no por obtener los parabienes de alguna agencia concreta, especie que goza de una gran 
fortuna en una comunidad académica en la cual, de un tiempo a esta parte, todos jugamos a evaluarnos a todos.

Nos parece por ello sumamente loable la publicación de un trabajo como el que comentamos en estas líneas, fruto de la mano experta de Soledad Gómez Navarro, profesora titular de Historia Moderna de la universidad de Córdoba, y que desde hace muchos años se ha dedicado con constancia, maestría y solidez, al estudio de la Iglesia y la vida religiosa en la Modernidad española. En esta ocasión, nos brinda la transcripción y el estudio introductorio del protocolo de los jerónimos de Valparaíso, conservado en el Archivo Histórico Provincial de Córdoba, ardua, ingrata, y no siempre bien entendida tarea la primera, provechoso y sin desperdicio el segundo.

La fuente analizada nos brinda una amplia cantidad de información, por cuanto se nos habla de propiedades rústicas, fincas urbanas, censos, testamentos, fundaciones de capellanías, privilegios de la corona, recibos y escrituras y memorias de misas. No obstante, son los aspectos de carácter económico los que reciben una mayor atención, lo que nos permite reconstruir perfectamente el proceso de consolidación del patrimonio de la comunidad jerónima, que hacia 1600 ya se encuentra prácticamente ultimado, gracias, entre otras cosas, a donaciones por parte de la nobleza y el clero. Todo ello nos muestra que nos encontramos con una comunidad muy beneficiada y privilegiada desde los primeros momentos de su existencia, constituyendo el momento culminante el reinado de los Reyes Católicos, monarcas especialmente favorecedores de la orden jerónima, como muestra su vinculación con el monasterio de Guadalupe. Pero el monasterio de Valparaíso no solamente se benefició de su relación con la monarquía, como revelan las frecuentes visitas de las que fue objeto por parte de los prelados cordobeses, traducidas en frecuentes donaciones de libros, alhajas o tapices. Esta posición privilegiada es un reflejo además de la procedencia social de los miembros de la comunidad, vinculados en muchas ocasiones a la nobleza local, siendo decisivo al respecto el papel jugado por el poderoso linaje de los Fernández de Córdoba.

En definitiva, el análisis del Protocolo nos revela algo que la autora del estudio señala muy acertadamente en las conclusiones del mismo: un monasterio es mucho más que una comunidad religiosa. Un monasterio es un centro de poder económico, vinculado básicamente a las élites locales, de la que proceden sus componentes, y al que benefician patrimonialmente por medio de legados y donaciones, a la vez que canaliza una porción del siempre lucrativo, al menos durante el Antiguo Régimen, mercado devocional, y juega un importante papel como referente artístico y cultural. Es el digno reflejo en este mundo de 
una institución que pretende tener una vocación de eternidad, y todo ello nos lo analiza la profesora Gómez Navarro con seriedad, maestría, y un gusto por el detalle minucioso tan raro en estos tiempos que corren dominados por el afán globalizador.

\author{
Arturo Morgado García
}

Universidad de Cádiz 